\title{
Age-specific COVID-19 case-fatality rate: no evidence of changes over time
}

\author{
Carlo Signorelli $i^{1}$ Anna Odone ${ }^{1}$
}

Received: 3 September 2020 / Accepted: 13 September 2020 / Published online: 25 September 2020

(c) Swiss School of Public Health (SSPH+) 2020

More than 5 months after the World Health Organization (WHO) declared the coronavirus infectious disease 2019 (COVID-19) outbreak a pandemic, and almost 900,000 deaths around the world, we are still far from fully understanding COVID-19 epidemiology and natural history. As we fear the consequences of second epidemic waves, as stated in a recent commentary (Middleton et al. 2020), it is not clear why the clinical burden of COVID-19 has decreased (Johns Hopkins University 2020). Experts claim this to be possibly related to infection transmission in younger age groups, as compared to the past (current average age of COVID-19 cases in Italy is 31 years versus 70 years in the first 2 months of the outbreak) (Italian National Institute of Health 2020), to decreased disease severity or to better therapeutic approaches.

National-level COVID-19 surveillance system data from Italy, the first European country to be hit by the COVID-19 outbreak and one of the countries with the highest number of reported cases and deaths in Europe (together with France, Spain and the UK) (Odone et al. 2020), are to be explored to better understand age-specific COVID-19 casefatality rate over time.

Table 1 reports the number of confirmed COVID-19 cases and deaths at, respectively, 2, 4 and 6 months since the onset of the epidemic, by age group. The large differences in case fatality rates by age (ranging from less than $3 \%$ in people younger than 60 years, up to more $30 \%$ in people 80 years or older) are well known and associated, among other factors, with higher rates of chronic comorbidities in elder populations. It also explains-as we have previously demonstrated-the high number of COVID-19 deaths in Italy, the country with one of the highest average age in the world (Signorelli et al. 2020).

More interestingly, as it emerges from Table 1, agespecific COVID-19 case-fatality rates seem not to vary over time, supporting the hypothesis that the less severe COVID-19 clinical outcomes (i.e. decreasing overall death rates) reported in recent times in Italy and Europe might be due to infection community transmission in younger populations.

We acknowledge the limitations linked to using surveillance data to derive insight on the COVID-19 epidemiology, linked to under-notification, heterogeneous testing strategies and time lag between notification and death (average time 12 days; Italian National Institute of Health 2020). Sill, we believe this data provide solid evidence to support the argument that should infection start to circulate again among older adults and elder populations (including those living in nursing homes), this might have detrimental clinical impacts in the weeks to come. If we add that no conclusive evidence has emerged so far on other potential factors influencing COVID-19 epidemiology, including the clinical effect of viral mutations or the impact of environmental temperature and weather conditions, it is of crucial importance to keep effective containment and mitigation measures in place and protect vulnerable subgroups of the population.
Carlo Signorelli

signorelli.carlo@hsr.it

1 School of Medicine, University Vita-Salute San Raffaele, Via Olgettina 60, 20132 Milan, Italy 
Table 1 COVID-19 cumulative deaths and case-fatality rates (CFRs) per age group at three different time points (Italy 2020)

\begin{tabular}{|c|c|c|c|c|c|c|c|c|c|}
\hline \multirow[b]{2}{*}{ Age group } & \multicolumn{3}{|c|}{ By April 16th } & \multicolumn{3}{|c|}{ By June 16 th } & \multicolumn{3}{|c|}{ By August 18th } \\
\hline & Deaths $(n)$ & CFR $(\%)$ & Cases $(n)$ & Deaths $(n)$ & CFR (\%) & Cases $(n)$ & Deaths $(n)$ & CFR (\%) & Cases $(n)$ \\
\hline $0-19$ & 1 & 0.0 & 2.927 & 4 & 0.1 & 5.843 & 4 & 0.1 & 8.516 \\
\hline $20-29$ & 7 & 0.1 & 7.737 & 15 & 0.1 & 13.673 & 16 & 0.1 & 16.757 \\
\hline $30-39$ & 40 & 0.3 & 11.686 & 65 & 0.3 & 18.755 & 67 & 0.3 & 21.293 \\
\hline $40-49$ & 178 & 0.9 & 20.519 & 286 & 0.9 & 31.057 & 313 & 0.9 & 33.462 \\
\hline $50-59$ & 756 & 2.5 & 29.858 & 1.159 & 2.7 & 42.704 & 1.241 & 2.8 & 44.775 \\
\hline $60-69$ & 2.284 & 9.5 & 24.040 & 3.367 & 10.6 & 31.777 & 3.592 & 10.9 & 33.097 \\
\hline $70-79$ & 6.203 & 24.1 & 25.717 & 8.830 & 26.0 & 33.916 & 9.335 & 26.7 & 34.925 \\
\hline$\geq 80$ & 10.525 & 28.8 & 36.519 & 19.483 & 32.3 & 60.317 & 21.275 & 34.6 & 61.436 \\
\hline Total & 19.996 & 12.6 & 159.107 & 33.209 & 13.9 & 238.082 & 35.843 & 14.1 & 254.283 \\
\hline
\end{tabular}

Acknowledgements This research is part of the EU Project no. 101003562 "Three Rapid Diagnostic tests (Point-of-Care) for COVID-19 Coronavirus, improving epidemic preparedness and foster public health and socio-economic benefits-CORONADX" supported by the European Commission (Horizon 2020, H2020-SC1PHE-CORONAVIRUS-2020).

\section{Compliance with ethical standards}

Conflict of interest The authors declare that they have no conflict of interest.

\section{References}

Italian National Institute of Health (2020) COVID-19 integrated surveillance system. https://www.epicentro.iss.it/coronavirus/ sars-cov-2-sorveglianza. Accessed 28 Aug 2020

Johns Hopkins University (2020) COVID-19 dashboard by the center for systems science and engineering. https://gisanddata.maps. arcgis.com/apps/opsdashboard/index.html\#/bda7594740fd40299 423467b48e9ecf6. Accessed 28 Aug 2020

Middleton J, Lopes H, Michelson K, Reid J (2020) Planning for a second wave pandemic of COVID-19 and planning for winter: a statement from the Association of Schools of Public Health in the European Region [published online ahead of print, 2020 Aug 28]. Int J Public Health 1-3. https://doi.org/10.1007/s00038-02001455-7

Odone A, Delmonte D, Scognamiglio T, Signorelli C (2020) COVID-19 deaths in Lombardy, Italy: data in context. Lancet Public Health. Apr 24, 2020. pii: S2468-2667(20)30099-2. https://doi.org/10. 1016/s2468-2667(20)30099-2. [Epub ahead of print] PubMed PMID: 32339478; PubMed Central PMCID: PMC7182509

Signorelli C, Odone A, Gianfredi V, Bossi E, Bucci D, OradiniAlacreu A, Frascella B, Capraro M, Chiappa F, Blandi L, Ciceri F (2020) COVID-19 mortality rate in nine high-income metropolitan regions. Acta Biomed 91(9-S):7-18. https://doi. org/10.23750/abm.v91i9-s.10134. PMID: 32701911

Publisher's Note Springer Nature remains neutral with regard to jurisdictional claims in published maps and institutional affiliations. 